\title{
Prior Cardiac Surgery Is Independently Associated With Decreased Survival Following Infant Tracheostomy
}

\author{
Elizabeth Rosner DO and Christopher W Mastropietro MD
}

\begin{abstract}
INTRODUCTION: Previous reports have demonstrated that prior cardiac surgery is independently associated with in-hospital mortality after infant tracheostomy. We aimed to determine whether these infants would continue to be at increased risk for death following hospital discharge. METHODS: A retrospective review was performed on subjects $<2$ y of age who recovered from tracheostomy in the pediatric ICU at our institution between January 2007 and December 2011, with follow-up to December 2013. Survival to $1 \mathrm{y}$ following tracheostomy was the primary outcome variable for the study. Multivariate Cox regression analysis was then performed to determine independent risk factors for death after infant tracheostomy. RESULTS: Forty-two subjects met inclusion criteria, 18 of whom had undergone prior cardiac surgery. Twenty-six subjects (62\%) were alive at $1 \mathrm{y}$ post-tracheostomy. Age at tracheostomy, concomitant genetic abnormalities or prematurity, and ventilator dependence at discharge were not statistically different between survivors and those who died. Subjects who died, however, were more likely to have had cardiac surgery prior to tracheostomy $(11[69 \%]$ vs $7[27 \%], P=.008)$ and had longer hospital stay (median 3.4 months [interquartile range: $2.6-4.6$ ] vs 2.2 months [interquartile range: $1.1-3.5$ ], $P=.045$ ). Multivariate Cox regression analysis revealed only prior cardiac surgery to be independently associated with decreased survival after tracheostomy (hazard ratio 4.7, 95\% CI 1.3-16.4, $P=.02$ ). CONCLUSIONS: Prior cardiac surgery is independently associated with decreased survival within $1 \mathrm{y}$ following tracheostomy. Clinicians and families of infants with prior cardiac surgery in whom tracheostomy after cardiac surgery is deemed necessary should consider this risk when planning long-term care. Key words: tracheostomy; pediatric; ventilators; mechanical; chronic lung injury; cardiac surgical procedures; heart defects; congenital. [Respir Care 2015;60(1):47-55. ( 2015 Daedalus Enterprises]
\end{abstract}

\section{Introduction}

Infants who require tracheostomies for long-term respiratory management often have additional co-morbidities

\footnotetext{
Dr Rosner is affiliated with the Department of Pediatrics, Division of Critical Care Medicine, Children's Hospital of Michigan/Wayne State University, Detroit, Michigan; Dr Mastropietro is affiliated with the Department of Pediatrics, Division of Critical Care Medicine, Riley Hospital for Children/Indiana University School of Medicine, Indianapolis, Indiana.
}

Dr Rosner presented a version of this research in poster format at the Annual Meeting of the Pediatric Academic Societies, held May 4-7, 2013, in Washington, DC.

The authors have no conflicts of interest to disclose. such as gastroesophageal reflux, developmental delay, chronic lung disease, and congenital or acquired heart disease. Some of these latter children also have, in addition to their underlying heart defect, other risk factors for the need for tracheostomy associated with their surgical repair or palliation procedure. Examples of such risk factors include vocal cord or diaphragmatic paresis/paralysis, tracheobronchomalacia resulting from chronic airway compression from cardiac structures, or chronic lung disease from com-

\footnotetext{
Correspondence: Christopher W Mastropietro MD, Associate Professor of Pediatrics, Indiana University School of Medicine, Medical Director of the Cardiovascular ICU, Riley Hospital for Children, Indianapolis, IN 46202. E-mail: cmastrop@iupui.edu.
}

DOI: $10.4187 /$ respcare. 03392 
plicated preoperative and postoperative courses. Several institutions have reported their experiences with pediatric subjects requiring tracheostomy following cardiac surgery. ${ }^{1-3}$ These reviews have reported a mortality rate of $34-47 \%$, significantly higher than the mortality rates reported in non-cardiac surgical populations. ${ }^{4-6}$ Two large multi-institutional studies performed by Berry and colleagues ${ }^{7,8}$ demonstrated increased risk of in-hospital mortality following tracheostomy in children with congenital heart disease, the majority of whom had undergone cardiac surgical repair or palliation. To our knowledge, no study to date has determined whether tracheostomy following pediatric cardiac surgery continues to be associated with poorer outcomes following hospital discharge relative to patients who require tracheostomy in association with other disease processes. Our aim was to examine outcomes in infants who undergo tracheostomy at our institution and identify factors that may negatively affect their survival. We hypothesized that infants who require tracheostomy following cardiac surgery would continue to have an increased risk of death following hospital discharge, despite similar post-tracheostomy care providers and parental education protocols to patients requiring tracheostomy in association with other illnesses.

\section{Methods}

\section{Study Population}

This study was approved by the institutional review boards of Wayne State University and the Detroit Medical Center, and all work was performed at Children's Hospital of Michigan (Detroit, Michigan). We performed a retrospective review of the medical records for all children $<2 \mathrm{y}$ of age who required a tracheostomy and recovered from the procedure in the pediatric ICU at Children's Hospital of Michigan from January 2007 to December 2011 with follow-up through December 2013. Patients who recovered from tracheostomy in the neonatal ICU, none of whom would have undergone prior cardiac surgery, were excluded to ensure similar care and education for all patients after tracheostomy. Additionally, at the time of study design, we were aware that, with the exception of one 15 -y-old child, all children who underwent tracheostomy after cardiac surgery at our institution during our study period were $<2$ y of age. Patients $>2$ y of age were therefore excluded to limit study heterogeneity.

Children's Hospital of Michigan is a 260-bed tertiary care center located in Detroit serving a diverse urban population. The pediatric cardiovascular surgeons perform approximately $250-300$ operations per year on patients with congenital heart lesions at all levels of complexity. The postoperative care of these patients is managed together by the cardiovascular surgeons and pediatric intensive care

\section{QUICK LOOK}

\section{Current knowledge}

Infants requiring tracheostomies for long-term respiratory management often have additional co-morbidities such as gastroesophageal reflux, chronic lung disease, and congenital or acquired heart disease. Previous reports have demonstrated that prior cardiac surgery is independently associated with in-hospital mortality after infant tracheostomy

\section{What this paper contributes to our knowledge}

Prior cardiac surgery was independently associated with decreased survival in infants requiring tracheostomy. The majority of deaths occurred within $1 \mathrm{y}$ of hospital discharge. Caregivers should be aware of the increased risk of mortality following discharge and the risk of sudden catastrophic events that can occur at home.

physicians. When tracheostomy placement is being considered for a patient in our pediatric ICU, a pediatric pulmonologist and pediatric otolaryngologist, if not yet involved in the patient's care, are consulted. The decision for tracheostomy is based on a patient's clinical course (eg, multiple failed extubation attempts, inability to wean from mechanical ventilation), results of direct laryngobronchoscopy, and multi-disciplinary discussions involving the pediatric intensive care team, pediatric pulmonologists and otolaryngologists, and the patient's family.

\section{Tracheostomy Preparation and Education}

The families of patients requiring tracheostomy meet with the otolaryngology nursing staff, pediatric pulmonologist, and social worker before the procedure to discuss and plan the immediate and long-term care of the patient. After the tracheostomy has been performed by a pediatric otolaryngologist, the primary caregiver from the family as well as a second caregiver undergoes educational training that includes cardiopulmonary resuscitation. The caregivers are given printed educational materials for use as a reference once they are at home that include information on suctioning, daily tracheostomy care, changing the tracheostomy tube, and cardiopulmonary resuscitation. The caregivers are also provided with a 20 -min video demonstrating each of these aspects of tracheostomy care. Two caregivers must do hands-on education and demonstrate that they can perform each of these tasks efficiently. After completing the training, each caregiver must stay in-hospital for at least one 12-h period where they alone provide all of the care for their child. If the patient requires home 
mechanical ventilation, the training also involves ventilator instruction by the respiratory therapists from the medical equipment company. Caregivers must be able to show how to assemble the ventilator before being discharged. For patients with only a tracheostomy, the teaching is typically completed in as few as $8-10 \mathrm{~d}$. For patients who require home mechanical ventilation, teaching and making the home ventilator-ready takes at least 1 month from the time the tracheostomy is performed. For these patients, transfer from the ICU to the pediatric pulmonology service occurs when patients are hemodynamically stable on consistent ventilator support. At this point in their course, the pediatric pulmonologists assume primary care of these patients and continue to direct ventilator management after hospital discharge. Only patients who are ventilatordependent have access to $8-12 \mathrm{~h}$ of home nursing care per day. This education program is similar to others that have been described previously and follows the guidelines for discharging a patient with a tracheostomy from the American Thoracic Society. ${ }^{9-11}$

\section{Data Collection and Analysis}

Data collected from the subject's course before tracheostomy included: age at admission, sex, weight, diagnoses cardiac surgical procedure (if applicable), indication for tracheostomy, co-morbidities, including prematurity (defined as less than 36 weeks' gestation), age at tracheostomy, duration of hospital stay before tracheostomy, duration of ventilator dependence before tracheostomy, and number of attempts at extubation. We also recorded Pediatric Index of Mortality-2 score at ICU admission, which is a validated and commonly used scoring system for rating the severity of medical illness for children. ${ }^{12}$ Data collected after tracheostomy included: duration of time from tracheostomy to hospital discharge or in-hospital death, ventilator support at time of discharge, duration of time from tracheostomy to death or the end of the study period, and location and circumstances of death.

Data are represented as mean with standard deviation for normally-distributed continuous variables, median with interquartile range for skewed continuous variables, and absolute counts with percentages for categorical variables. Bivariate analyses comparing who died within 1 y after tracheostomy placement with subjects who survived using $t$ tests for normally-distributed continuous variables, MannWhitney $\mathrm{U}$ tests for skewed continuous variables, and chi-square tests for categorical variables. The primary outcome variable of the study was death at $1 \mathrm{y}$ post-tracheostomy. A Cox proportional hazards regression analysis was performed to determine independent risk factors for mortality within 1 y of tracheostomy. Variables with $P \leq .1$ on bivariate analysis comparing subjects who died to subjects alive at $1 \mathrm{y}$ were considered for the multivariate model. Additional bivariate analyses comparing patients with tracheostomy and a history of prior cardiac surgery with those without a history of prior cardiac surgery were performed. Kaplan-Meier survival curves for subjects with prior cardiac surgery and without prior cardiac surgery were generated and compared using log rank test. The program used for the initial statistical analyses was Stata IC/13.0 (StataCorp, College Station, Texas). A biostatistician then confirmed all statistical analyses using SAS 9.3 (SAS Institute, Cary, North Carolina), and also tested the proportional hazards assumption using SAS's phreg procedure, which computed the $P$ value of a Kolmogorovtype supremum test. These tests were based on a sample of 10,000 simulated residual patterns and had a nonsignificant $P$ value $>.05$.

\section{Results}

Forty-two subjects were included in the study. Eighteen of these subjects (43\%) had a history of prior cardiac surgery, whereas no subjects had cardiac surgery after tracheostomy. The most common indications for tracheostomy were tracheobronchomalacia $(n=17)$ and extrathoracic airway obstruction $(n=19)$. Other indications for tracheostomy included neuromuscular weakness, pulmonary hypertension, chronic lung disease, diaphragmatic paresis, and central hypoventilation. Median number of extubation attempts for all subjects was 1 , with a range of 0-6 attempts. In other words, some subjects never met criteria for extubation while others underwent multiple attempts before tracheostomy was pursued.

Twenty-six subjects (62\%) were alive 1 y after tracheostomy. Characteristics of survivors and subjects who died are compared in Table 1. Subjects who died within $1 \mathrm{y}$ after tracheostomy had a significantly longer cumulative hospital stay (ie, from ICU admission to death or discharge after tracheostomy) and were more likely to have had cardiac surgery. The results of a Cox regression survival analysis are provided in Table 2. History of prior cardiac surgery and cumulative hospital stay, the two variables found to be significantly different in our bivariate analysis of survivors versus non-survivors at 1 y after tracheostomy, were included in the regression model. Only cardiac surgery had a significant effect on death, such that subjects undergoing tracheostomy after cardiac surgery were nearly 5 times more likely to die within $1 \mathrm{y}$ after tracheostomy as compared with subjects requiring tracheostomy in association with other disease processes.

Characteristics of subjects with a history of prior cardiac surgery are compared with subjects without cardiac surgery in Table 3. Subjects with a history of prior cardiac surgery were significantly younger, were more likely to have tracheobronchomalacia as the underlying indication for their tracheostomy, and were more likely to be venti- 
Table 1. Subject Characteristics Based on Status at 1 y Post-Tracheostomy

\begin{tabular}{|c|c|c|c|}
\hline Variables* & $\begin{array}{l}\text { Survived } \\
(n=26)\end{array}$ & $\begin{array}{c}\text { Died } \\
(n=16)\end{array}$ & $P$ \\
\hline Age at ICU admission (mo) & $7.6(5.9)$ & $6.2(5.7)$ & .48 \\
\hline Male sex & $17(65)$ & $8(50)$ & .32 \\
\hline Prematurity & $10(38)$ & $3(19)$ & .18 \\
\hline Chromosomal abnormalities & $11(42)$ & $5(31)$ & .48 \\
\hline PIM-2 at ICU admission $\dagger$ & $3.3(1-8.9)$ & $2.1(1.7-4)$ & .61 \\
\hline History of cardiac surgery & $7(27)$ & $11(69)$ & .008 \\
\hline Tracheobronchomalacia & $9(35)$ & $8(50)$ & .32 \\
\hline Extrathoracic airway obstruction & $13(50)$ & $6(38)$ & .43 \\
\hline Extubation attempts $(n)$ & $1.5(1.5)$ & $1.9(1.8)$ & .37 \\
\hline Age at tracheostomy $(\mathrm{mo})$ & $8.5(5.7)$ & $7.5(5.6)$ & .59 \\
\hline ICU admission to tracheostomy placement (d) $\dagger$ & $27(15-52)$ & $32(26-70)$ & .09 \\
\hline Tracheostomy to discharge or death (d) $\dagger$ & $32(20-46)$ & $47(35-60)$ & .12 \\
\hline Cumulative hospital length of stay (mo) $\dagger$ & $2.2(1.1-3.5)$ & $3.4(2.6-4.6)$ & .05 \\
\hline Ventilator-dependent at discharge or death & $16(62)$ & $12(75)$ & .81 \\
\hline Age of primary caregiver $(\mathrm{y})$ & $26(6.7)$ & $28(8.6)$ & .44 \\
\hline $\begin{array}{l}\ddagger \text { Pre-tracheostomy duration of mechanical ventilation. } \\
\text { PIM-2 = Pediatric Index of Mortality-212 }\end{array}$ & $\begin{array}{l}\text { * Continuous variables are represented as mean (standard deviation), and categorical data are listed as } n(\%) \text { unless otherwise noted. Statistical significance was set at } P<.05 \text {. } \\
\dagger \text { Median (interquartile range). }\end{array}$ & gnificance was set at $I$ & \\
\hline
\end{tabular}

Table 2. Cox Proportional Hazards Regression Analysis

\begin{tabular}{lcrr}
\hline \hline \multicolumn{1}{c}{ Variable } & Hazard Ratio & \multicolumn{1}{c}{$95 \%$ CI } & $P$ \\
\hline Prior cardiac surgery & 4.7 & $1.3-16.4$ & .02 \\
Cumulative hospital stay* & 0.9 & $0.70-1.16$ & .43
\end{tabular}

$\bar{*}$ ICU admission-to-tracheostomy plus tracheostomy-to-discharge or in-hospital death

lator-dependent at hospital discharge. None of these 3 variables, however, when added to the Cox proportional hazards regression model, independently impacted survival or appreciably altered the results provided in Table 2 (data not shown). More detailed characteristics of those subjects who underwent tracheostomy after cardiac surgery and who underwent tracheostomy in association with other diagnoses are provided in Tables 4 and 5, respectively. Four more subjects died between $1 \mathrm{y}$ after insertion of their tracheostomies and the end of the study period, 3 of whom had a history of prior cardiac surgery. In Figure 1, a Kaplan-Meier curve shows the survival up to $2 \mathrm{y}$ following tracheostomy, comparing subjects requiring tracheostomy after cardiac surgery with those subjects requiring tracheostomy not in association with cardiac surgery. Survival is markedly decreased in those subjects who underwent cardiac surgery (log rank test, $P=.002$ ). The majority of subjects in both of these groups survived to hospital discharge: 16 of $18(89 \%)$ in subjects with prior cardiac surgery and 23 of $24(96 \%)$ in subjects without, $P=.57$. Mortality after discharge, however, was significantly higher in those subjects who underwent cardiac surgery (12 of 16,
$75 \%$ ), as compared with those who did not (5 of $23,22 \%$ ), $P$ value $<.001$. Of note, all subjects with systemic-topulmonary artery shunts (for single-ventricle anatomy or tetralogy of Fallot) died after hospital discharge within 1 y of tracheostomy insertion.

Overall, there were 102.5 person-years of follow-up throughout the study period, 27.4 person-years in subjects who underwent cardiac surgery and 75.1 person-years in subjects without a history of cardiac surgery. The incidence rates for overall and post-discharge mortality in patients with a history of cardiac surgery were 5.1 per 10 person-years and 5.0 per 10 person-years, respectively; in contrast, the incidence rates for overall and post-discharge mortality in subjects without cardiac surgery were 0.8 per 10 person-years and 0.7 per 10 person-years, respectively.

Of the subjects with prior cardiac surgery who survived to hospital discharge, 7 of 16 (35\%) died suddenly either at home or in the emergency department after having a sudden cardiopulmonary arrest at home, while 3 of 23 non-cardiac surgical subjects (9\%) died in similar acute circumstances, $P=.06$. Median time from discharge to death for the 7 infants with a history of cardiac surgery was $27 \mathrm{~d}$ (range: $2 \mathrm{~d}$ to $51 \mathrm{mo}$ ). All of these subjects had electrocardiograms and echocardiograms just before discharge. One of the 7 subjects with a history of cardiac surgery who died unexpectedly at home had moderate atrioventricular valve regurgitation, 1 subject had moderate pulmonary valve insufficiency, and 1 subject had intraventricular conduction delay on electrocardiogram and was discharged home on amiodarone. Event histories 


\section{CARdiac Surgery and Tracheostomy in Infants}

Table 3. Characteristics of Subjects With a History of Cardiac Surgery Prior to Tracheostomy Insertion Compared to Subjects With No History of Prior Cardiac Surgery

\begin{tabular}{|c|c|c|c|}
\hline Variables* & Cardiac Surgery $(n=18)$ & No Cardiac Surgery $(n=24)$ & $P$ \\
\hline Age at ICU admission (mo) & $1.8(1.2-7.3)$ & $8.1(3.4-14.2)$ & $<.001$ \\
\hline Male sex & $9(50)$ & $16(67)$ & .28 \\
\hline Prematurity & $3(17)$ & $10(42)$ & .10 \\
\hline Chromosomal abnormalities & $7(39)$ & $9(38)$ & .93 \\
\hline PIM-2 at ICU admission & $2.2(1.8-3.6)$ & $3.3(0.9-10.4)$ & .88 \\
\hline Tracheobronchomalacia & $13(72)$ & $4(16)$ & $<.001$ \\
\hline Extrathoracic airway obstruction & $15(63)$ & $(22)$ & .01 \\
\hline Extubation attempts ( $n$, range) & $1.5(0-6)$ & $1(0-5)$ & .47 \\
\hline Age at tracheostomy (mo) & $3.6(2.4-9)$ & $9.4(4.5-15.5)$ & .03 \\
\hline ICU admission to tracheostomy placement $(\mathrm{d}) \dagger$ & $46.5(30-81)$ & $17.5(13-30)$ & $<.001$ \\
\hline Tracheostomy to discharge/death (d) & $53.6(35-75)$ & $28.5(19-44)$ & .002 \\
\hline Cumulative hospital length of stay (mo) & $4.3(3.3-6.2)$ & $1.6(0.9-2.4)$ & $<.001$ \\
\hline Ventilator-dependent at discharge or death & $17(95)$ & $11(46)$ & .001 \\
\hline Mortality prior to hospital discharge & $2(11)$ & $1(4)$ & .57 \\
\hline Mortality at $1 \mathrm{y}$ after tracheostomy & $12(67)$ & $5(21)$ & .008 \\
\hline \multicolumn{4}{|c|}{$\begin{array}{l}\text { * Continuous variables are represented as median (interquartile range) unless otherwise noted, and categorical data are listed as } n(\%) \text {. } \\
\dagger \text { Pre-tracheostomy duration of mechanical ventilation. } \\
\text { PIM-2 }=\text { Pediatric Index of Mortality-2 } 2^{12}\end{array}$} \\
\hline
\end{tabular}

provided by the parents of these infants were available for all 7 subjects. For 4 infants, the family simply reported that they found their children unresponsive, and upon arrival of medical personnel, the children were found to be pulseless. One subject reportedly had normal vital signs just before a nurse left the home, and was found later in the day to be cold and cyanotic by the mother, who called 911 . Another subject reportedly became uncomfortable "during a breathing treatment," for which the mother called the on-call respiratory therapist because she thought "something was wrong with the ventilator." She was instructed to ventilate the subject with a manual resuscitation bag and call 911, but the infant decompensated further by the time emergency medical personnel arrived and was pronounced dead at an outside emergency department. The last subject who died suddenly was reported to have been coughing and "turned blue," for which the home nurse changed the tracheostomy tube but no clinical improvement occurred. Upon arrival of emergency medical personnel, the infant was cyanotic with absent vital signs. Autopsy reports were available for 4 of these 7 infants. No autopsy report found evidence of a cardiovascular cause of death such as shunt occlusion, conduit obstruction, or ventricular outflow tract obstruction.

\section{Discussion}

This report demonstrates that prior cardiac surgery is independently associated with decreased survival in infants within $1 \mathrm{y}$ of requiring tracheostomy. This study is consistent with previous studies that report a high mortal- ity rate in subjects undergoing tracheostomy in association with cardiac surgery. ${ }^{1-3}$ To our knowledge, this is the first study to demonstrate that this increased risk, as compared with a population without cardiac surgery with similar care and caregiver education after tracheostomy, persists following discharge from the hospital. In fact, at our institution, in-hospital mortality was not statistically different between these two cohorts, and the survival disadvantage observed in subjects with prior cardiac surgery did not become apparent until after hospital discharge. Additionally, our study provides important information regarding the timing and location of death for these infants, revealing that a considerable number of the deaths in subjects undergoing tracheostomy after cardiac surgery occurred at home or in the emergency department following cardiopulmonary arrest at home, some within days after discharge.

In a large cohort of children with various illnesses requiring tracheostomy with home mechanical ventilation, Edwards and colleagues ${ }^{13}$ reported mortality in 47 of 228 subjects and half of these mortalities were described as unexpected. Neither congenital heart disease nor a history of pediatric cardiac surgery was examined as a potential risk factor for mortality in this study. However, many of the deaths in this study were described as "cardiac" in nature, and the majority of the unexpected deaths were considered to not be related to the tracheostomies themselves but rather to the progression of the subjects' underlying disease processes. Based on the histories available for the sudden unexpected deaths in our cohort, some of the events may have been triggered by mechanical com- 


\section{Cardiac Surgery and Tracheostomy in Infants}

Table 4. Subjects Who Required Tracheostomy After Cardiac Surgery

\begin{tabular}{|c|c|c|c|c|}
\hline $\begin{array}{c}\text { Subject } \\
\text { no. }\end{array}$ & Cardiac Defect/Primary Surgery & Tracheostomy Indication(s) & Comorbidities & Overall Outcome \\
\hline 1 & Aortic coarctation, VSD/definitive repair & $\begin{array}{l}\text { Left bronchomalacia, } \\
\text { neuromuscular weakness }\end{array}$ & Trisomy 18 & Alive \\
\hline 2 & TA/RV-to-PA conduit & Tracheobronchomalacia & Prematurity, DiGeorge syndrome & $\begin{array}{l}\text { Alive } 30 \text { mo after tracheostomy, } \\
\text { lost to follow-up }\end{array}$ \\
\hline 3 & Critical PS/transannular patch & Persistent glottic edema & Prematurity & Alive \\
\hline 4 & $\begin{array}{l}\text { ASD, VSD, aortic root deviation/ } \\
\text { ASD-VSD closure, PA-plasty }\end{array}$ & $\begin{array}{l}\text { Tracheobronchomalacia, } \\
\text { pulmonary hypertension }\end{array}$ & $\begin{array}{l}\text { Hydrocephalus, anoxic } \\
\text { encephalopathy }\end{array}$ & $\begin{array}{l}\text { Died after readmission, } 9.3 \mathrm{mo} \\
\text { after tracheostomy }\end{array}$ \\
\hline 5 & AVSD/definitive repair & Bronchomalacia & $\begin{array}{l}\text { Trisomy } 21 \text {, complete heart } \\
\text { block }\end{array}$ & $\begin{array}{l}\text { Died after readmission, } 3.7 \mathrm{mo} \\
\text { after tracheostomy }\end{array}$ \\
\hline 6 & VSD/PA banding & Tracheomalacia & $\begin{array}{l}\text { Chromosome } 3 p \text { deletion, } \\
\text { imperforate anus }\end{array}$ & $\begin{array}{l}\text { Died after readmission, } 6.9 \text { mo } \\
\text { after tracheostomy }\end{array}$ \\
\hline 7 & TOF, absent $\mathrm{PV} /$ definitive repair & Bronchomalacia & & $\begin{array}{l}\text { Died at home, } 18 \text { mo after } \\
\text { discharge }\end{array}$ \\
\hline 8 & DORV, TGA, PS/RV-to-PA conduit & Tracheobronchomalacia & Hydrocephalus & $\begin{array}{l}\text { Died at home, } 3 \mathrm{~d} \text { after } \\
\text { discharge }\end{array}$ \\
\hline 9 & TA, RV-to-PA conduit & Tracheobronchomalacia & Choanal atresia, rib abnormalities & $\begin{array}{l}\text { Died at home, } 27 \mathrm{~d} \text { after } \\
\text { discharge }\end{array}$ \\
\hline 10 & TOF with AVSD/definitive repair & Severe subglottic stenosis & $\begin{array}{l}\text { Down syndrome, complete heart } \\
\text { block }\end{array}$ & $\begin{array}{l}\text { Died during initial admission, } \\
2 \text { mo after tracheostomy }\end{array}$ \\
\hline 11 & $\begin{array}{l}\text { TOF, pulmonary atresia, MAPCAs/ } \\
\text { systemic-to-PA shunt }\end{array}$ & Tracheobronchomalacia & Hydrocephalus & $\begin{array}{l}\text { Died at home, } 2 \mathrm{~d} \text { after } \\
\text { discharge }\end{array}$ \\
\hline 12 & $\begin{array}{l}\text { PA, anbalanced AVSD/unifocalization, } \\
\text { systemic-to-PA shunt }\end{array}$ & Right bronchomalacia & NA & $\begin{array}{l}\text { Died at home, } 5 \mathrm{~d} \text { after } \\
\text { discharge }\end{array}$ \\
\hline 13 & $\begin{array}{l}\text { PA, Ebstein's anomaly/systemic-to-PA } \\
\text { shunt, fenestrated closure of TV }\end{array}$ & Tracheobronchomalacia & Hepatic dysfunction & $\begin{array}{l}\text { Died after readmission, } 4 \text { mo } \\
\text { after tracheostomy }\end{array}$ \\
\hline 14 & TOF/systemic-to-PA shunt & $\begin{array}{l}\text { Right bronchomalacia, left } \\
\text { bronchial stenosis }\end{array}$ & $\begin{array}{l}\text { Prematurity, tracheoesophageal } \\
\text { fistula }\end{array}$ & $\begin{array}{l}\text { Died at home } 11 \text { mo after } \\
\text { discharge }\end{array}$ \\
\hline 15 & $\begin{array}{l}\text { DORV/Damus-Kaye-Stansel procedure, } \\
\text { systemic-to-PA shunt }\end{array}$ & Chronic lung disease & $\begin{array}{l}\text { Chromosome } 8 \text { anomaly } \\
\text { Ventriculoperitoneal shunt }\end{array}$ & $\begin{array}{l}\text { Died during initial admission, } \\
4 \text { mo after tracheostomy }\end{array}$ \\
\hline 16 & TA, IAA/heart transplant & Subglottic stenosis & $\begin{array}{l}\text { Pulmonary hypertension, } \\
\text { DiGeorge syndrome }\end{array}$ & $\begin{array}{l}\text { Died at home } 51 \mathrm{mo} \text { after } \\
\text { discharge }\end{array}$ \\
\hline 17 & TA/heart transplant & Tracheomalacia & NA & Alive \\
\hline 18 & $\mathrm{HCM} /$ heart transplant & Severe left bronchomalacia & Pectus carinatum & $\begin{array}{l}\text { Died after readmission, } 3 \text { mo } \\
\text { after tracheostomy }\end{array}$ \\
\hline 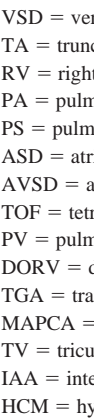 & $\begin{array}{l}\text { tricular septal defect } \\
\text { cus arteriosus } \\
\text { ventricle } \\
\text { onary artery } \\
\text { onary stenosis } \\
\text { ial septal defect } \\
\text { trioventricular septal defect } \\
\text { alogy of Fallot } \\
\text { lonary valve } \\
\text { louble outlet right ventricle } \\
\text { nsposition of the great arteries } \\
\text { major aortopulmonary collateral artery } \\
\text { spid valve } \\
\text { prupted aortic arch } \\
\text { pertrophic cardiomyopathy }\end{array}$ & & & \\
\hline
\end{tabular}

plications, but the end results were more likely to be related to the underlying disease burden of each subject. Indeed, the high mortality rates observed in children following cardiac surgery seen in our study as well as at other institutions ${ }^{1-3}$ are most likely due to the cumulative discharge morbidities present in this patient population. Infants requiring tracheostomy after cardiac surgery by def- inition have some degree of both respiratory and cardiac disease. For many patients, residual cardiac disease remains following surgery. For example, patients with tetralogy of Fallot continue to have right ventricular diastolic dysfunction for months to years following repair. ${ }^{14}$ Infants undergoing cardiac surgery often have abnormalities in other organ systems that are less common in infants 


\section{Cardiac Surgery and Tracheostomy in Infants}

Table 5. Subjects Requiring Tracheostomy Without Associated Cardiac Surgery

\begin{tabular}{|c|c|c|c|c|}
\hline $\begin{array}{l}\text { Subject } \\
\text { No. }\end{array}$ & Primary Diagnosis & Tracheostomy Indication(s) & Comorbidities & Overall Outcome \\
\hline 1 & Central hypoventilation & Central hypoventilation & FTT, GERD, hypotonia & Alive \\
\hline 2 & Pompe disease & Neuromuscular weakness & FTT & Alive \\
\hline 3 & Pompe disease & Neuromuscular weakness & FTT & Alive \\
\hline 4 & Laryngomalacia & Laryngomalacia, subglottic stenosis & GERD & Alive \\
\hline 5 & Traumatic brain injury & Inability to protect airway & Severe encephalomalacia & Alive \\
\hline 6 & Traumatic brain injury & $\begin{array}{l}\text { Subglottic edema, left vocal cord } \\
\text { paresis }\end{array}$ & $\begin{array}{l}\text { Seizures, autonomic } \\
\text { dysfunction, } \\
\text { ventriculoperitoneal shunt }\end{array}$ & Alive \\
\hline 7 & Subglottic stenosis & $\begin{array}{l}\text { Subglottic stenosis, severe } \\
\text { tracheobronchomalacia }\end{array}$ & Prematurity & Alive \\
\hline 8 & Prematurity & Subglottic stenosis, BPD & $\begin{array}{l}\text { BPD, pulmonary hypertension, } \\
\text { grade III IVH }\end{array}$ & $\begin{array}{l}\text { Died after readmission, } 3 \mathrm{mo} \\
\text { after tracheostomy }\end{array}$ \\
\hline 9 & Prematurity & Pulmonary hypertension, BPD & BPD, pulmonary hypertension & Alive \\
\hline 10 & RSV bronchiolitis & Subglottic stenosis & & Alive \\
\hline 11 & $\begin{array}{l}\text { Right lung agenesis, complete } \\
\text { tracheal rings }\end{array}$ & Tracheal stenosis & $\mathrm{BPD}$, prematurity & Alive \\
\hline 12 & $\begin{array}{l}\text { Chromosomal abnormalities of } \\
\text { chromosomes } 11 \text { and } 18\end{array}$ & Severe laryngotracheomalacia & $\begin{array}{l}\text { Prematurity, dysplastic } \\
\text { tricuspid valve }\end{array}$ & $\begin{array}{l}\text { Died at home, } 13 \text { mo after } \\
\text { tracheostomy }\end{array}$ \\
\hline 13 & Loeys-Dietz syndrome & Diaphragmatic paresis & Cleft lip and palate hypotonia & Alive \\
\hline 14 & $\begin{array}{l}\text { Inverted chromosomal } \\
\quad \text { duplication: } 1 \mathrm{q} 32 \text { to } 1 \mathrm{q} 44\end{array}$ & Laryngotracheobronchomalacia & $\begin{array}{l}\text { BPD, prematurity, } \\
\text { ventriculoperitoneal shunt }\end{array}$ & Alive \\
\hline 15 & $\begin{array}{l}\text { Pulmonary artery sling, } \\
\text { complete tracheal rings }\end{array}$ & Tracheal stenosis & NA & Alive \\
\hline 16 & Prematurity & $\begin{array}{l}\text { Severe left bronchomalacia, } \\
\text { subglottic stenosis }\end{array}$ & $\begin{array}{l}\text { BPD, pulmonary hypertension, } \\
\text { grade III IVH }\end{array}$ & Alive \\
\hline 17 & Mitochondrial myopathy & Hypotonia, airway protection & NA & $\begin{array}{l}\text { Died during initial admission, } \\
2 \text { mo after tracheostomy }\end{array}$ \\
\hline 18 & Spinal muscular atrophy type 1 & Neuromuscular weakness & NA & Alive \\
\hline 19 & Anoxic encephalopathy & Recurrent subglottic cyst & Seizures, prematurity & $\begin{array}{l}\text { Died after readmission, } \\
1.3 \text { mo after tracheostomy }\end{array}$ \\
\hline 20 & Septo-optic dysplasia & Severe obstructive sleep apnea & Pulmonary hypertension & Alive \\
\hline 21 & Subglottic stenosis & Subglottic stenosis & GERD & $\begin{array}{l}\text { Died at home, } 10 \mathrm{~d} \text { after } \\
\text { discharge }\end{array}$ \\
\hline 22 & Vascular ring & Glottic edema, tracheitis & $\begin{array}{l}\text { Chromosome } 3 \text { duplication, } \\
\text { facial anomalies }\end{array}$ & Alive \\
\hline 23 & RSV bronchiolitis & Severe subglottic stenosis & Prematurity, grade I IVH & $\begin{array}{l}\text { Died at home, } 9 \text { mo after } \\
\text { tracheostomy }\end{array}$ \\
\hline 24 & Prematurity & $\begin{array}{l}\text { Severe CLD, pulmonary } \\
\text { hypertension }\end{array}$ & BPD, pulmonary hypertension & Alive \\
\hline $\begin{array}{l}\text { FTT }=\text { fail } \\
\text { GERD }=\text { g: } \\
\text { BPD }=\text { bro } \\
\text { IVH }=\text { intra } \\
\text { RSV }=\text { rest } \\
\text { NA }=\text { not a } \\
\text { CLD }=\text { chr }\end{array}$ & $\begin{array}{l}\text { to thrive } \\
\text { roesophageal reflux disease } \\
\text { hopulmonary dysplasia } \\
\text { entricular hemorrhage } \\
\text { atory syncitial virus } \\
\text { plicable } \\
\text { ic lung disease }\end{array}$ & & & \\
\hline
\end{tabular}

with primarily respiratory disease. For example, many often suffer concomitant neurologic and renal injuries during and after surgery related to exposure to cardiopulmonary bypass and postoperative hemodynamic instability. ${ }^{15,16}$ As a result of all of the aforementioned co-morbidities, these patients likely have less reserve as compared with other patients and therefore are less likely to tolerate respiratory complications that may occur at home such as a mucus plug or dislodgment of their artificial airway. ${ }^{17}$ The higher rate of home mechanical ventilation in patients with cardiac surgery, although not independently associated with mortality, does mandate a much higher level of care for many of these infants and should not be dismissed as a possible contributing factor. Caregivers of patients requiring home mechanical ventilation must not only know how to care for the tracheostomy tube but also understand the 


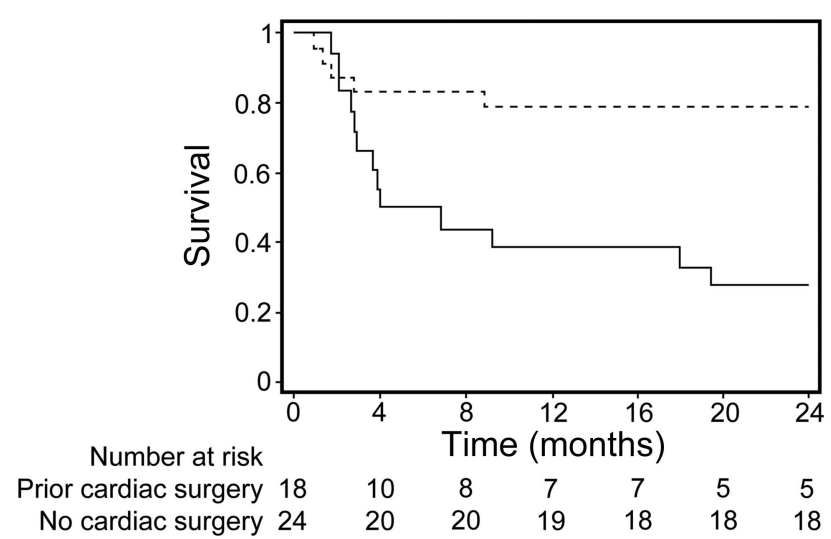

Fig. 1. Kaplan-Meier survival curve. Survival of patients after tracheostomy after cardiac surgery (solid line) is significantly lower than for patients with tracheostomy in association with other disease states (dashed line), log rank test $P=.002$.

complexities of how to use, maintain, and troubleshoot a mechanical ventilator. ${ }^{18}$ As the level of care for the patient increases, so does the level of stress and likelihood of complications.

Due to the poor outcomes associated with tracheostomy in cardiac surgical subjects reported in this study and others, the option of tracheostomy should be thoroughly discussed and alternatives should be considered if possible. On the other hand, if there is no alternative to tracheostomy or it is decided by the team caring for a patient and family that tracheostomy is the best option, a more extensive discharge education plan and closer home monitoring program may be warranted. Berry and colleagues ${ }^{7}$ previously reported that extended hospital stays post-tracheostomy in children requiring home mechanical ventilation did not affect survival, although this study did not examine the effect of extended hospital stays on the subset of subjects with prior cardiac surgery. In our study, however, subjects who died were more likely to have longer postoperative stays than those who survived. We therefore speculate that the stay following tracheostomy may be less important than the discharge teaching and education provided to the children's caregivers during this time period. Considering the high mortality rates that have been consistently reported in infants and children with a history of prior cardiac surgery, the development of consensus guidelines on parental counseling and discharge planning procedures specific to this patient population seems warranted. A national database of all infants undergoing tracheostomy could also be helpful, with the goal of further identifying patient characteristics that can differentiate optimal from poor candidates for the procedure.

Our study has limitations inherent to its retrospective design. For example, more detailed information on the causes of death would have been helpful. Further, our study represents the results of a single center's experience, which may not be generalizable to all centers. The high mortality rates seen in our study, however, are similar to the previously published mortality rates at other centers. ${ }^{1-3}$ The single-center nature of the study also ensures that postoperative care and parental education was similar for all patients. Another study limitation concerns our decision to exclude infants who underwent tracheostomy placement and tracheostomy recovery in the neonatal ICU at our institution. Although this decision was made to limit variation in the care and education received by the subjects and their families following tracheostomy placement, we acknowledge that this exclusion could bias our results by eliminating a number of complex infants without a history of cardiac surgery from our study. A multi-centered study in which the location of post-tracheostomy care (eg, neonatal vs pediatric ICU) is included as a potential confounding variable should be pursued to confirm our results. Finally, the small number of subjects in our study limits both the precision of its statistical design and the number of potential confounding variables that could be identified and analyzed.

\section{Conclusions}

Prior cardiac surgery was independently associated with decreased survival in infants requiring tracheostomy, the majority of which occurred after hospital discharge within $1 \mathrm{y}$ of the procedure. With this knowledge, every effort should be made to optimize each patient's underlying cardiac physiology before proceeding with tracheostomy. This increased risk of mortality should also be thoroughly discussed with families of infants in whom tracheostomy after cardiac surgery is considered. Caregivers of these children should not only be aware of increased risk of mortality following discharge but also of the risk of sudden catastrophic events that can occur at home.

\section{ACKNOWLEDGMENTS}

We thank James Edward Slaven MSc, Department of Biostatistics, Indiana University-Purdue University, Indianapolis, Indiana, for assistance with confirmation of the results of statistical analyses in this manuscript.

\section{REFERENCES}

1. Hoskote A, Cohen G, Goldman A, Shekerdemian L. Tracheostomy in infants and children after cardiothoracic surgery: indications, associated risk factors, and timing. J Thorac Cardiovasc Surg 2005; 130(4):1086-1093.

2. Edwards J, Kun S, Keens T, Khemani R, Moromisato D. Children with corrected or palliated congenital heart disease on home mechanical ventilation. Pediatr Pulmonol 2010;45:645-649.

3. Cotts T, Hirsch J, Thorne M, Gajarski R. Tracheostomy after pediatric cardiac surgery: frequency, indications, and outcomes. J Thorac Cardiovasc Surg 2011;141:413-418. 


\section{Cardiac Surgery and Tracheostomy in Infants}

4. Wetmore RF, Handler SD, Potsic WP. Pediatric tracheostomy: experience during the past decade. Ann Otol Rhinol Laryngol 1982; 91:628-632.

5. Ward R, Jones J, Carew J. Current trends in pediatric tracheotomy. Int J Pediatr Otorhinolaryngol 1995;32(3):233-239.

6. Alladi A, Rao S, Das K, Charles AR, D'Cruz AJ. Pediatric tracheosotmy: a 13-year experience. Pediatr Surg Int 2004;20:695-698.

7. Berry J, Graham D, Graham R, Zhou J, Putney H, O’Brien J, et al. Predictors of clinical outcomes and hospital resource use of children after tracheostomy. Pediatrics 2009;124(2):563-572.

8. Berry J, Graham R, Roberson D, Rhein L, Graham D, Zhou J, et al. Patient characteristics associated with in-hospital mortality in children following tracheotomy. Arch Dis Child 2010;95:703-710.

9. Tearl DK, Hertzog JH. Home discharge of technology-dependent children: evaluation of a respiratory-therapist driven family education program. Respir Care 2007;52(2):171-176.

10. Graf JM, Montagnino BA, Hueckel R, McPherson ML. Children with new tracheostomies: planning for family education and common impediments to discharge. Pediatr Pulmonol 2008;43:788794.

11. ATS Board of Directors. Care of the child with a chronic tracheostomy. Am J Respir Crit Care Med 2000;161:297-308.
12. Degli Atti ML, Cuttini M, Ravà L, Rinaldi $\mathrm{S}$, Brusco $\mathrm{C}$, Cogo $\mathrm{P}$, et al. Performance of the pediatric index of mortality 2 (PIM-2) in cardiac and mixed intensive care units in a tertiary children's referral hospital in Italy. BMC Pediatr 2013;13(1):100.

13. Edwards JD, Kun SS, Keens TG. Outcomes and causes of death in children on home mechanical ventilation via tracheostomy: an institutional and literature review. J Pediatr 2010;157(6):955-959.

14. Newburger J, Bellinger D. Brain injury in congenital heart disease. Circulation 2006;113(2):183-185.

15. Li S, Krawczeski CD, Zappitelli M, Devarajan P, Thiessen-Philbrook $\mathrm{H}$, Coca SG, et al. Incidence, risk factors, and outcomes of acute kidney injury after pediatric cardiac surgery: a prospective multicenter study. Crit Care Med. 2011;39(6):1493-1499.

16. Chaturvedi RR, Shore DF, Lincoln C, Mumby S, Kemp M, Brierly $\mathrm{J}$, et al. Acute right ventricular restrictive physiology after repair of tetralogy of Fallot: association with myocardial injury and oxidative stress. Circulation 1999;100(14):1540-1547.

17. Kremer B, Botos-Kremer A, Eckel H, Schlöndorff G. Indications, complications, and surgical techniques for pediatric tracheostomies: an update. J Pediatr Surg 2002;37:1556-1562.

18. American Thoracic Society. Home mechanical ventilation of pediatric patients. Am Rev Respir Dis 1990;141(1): 258-259. 